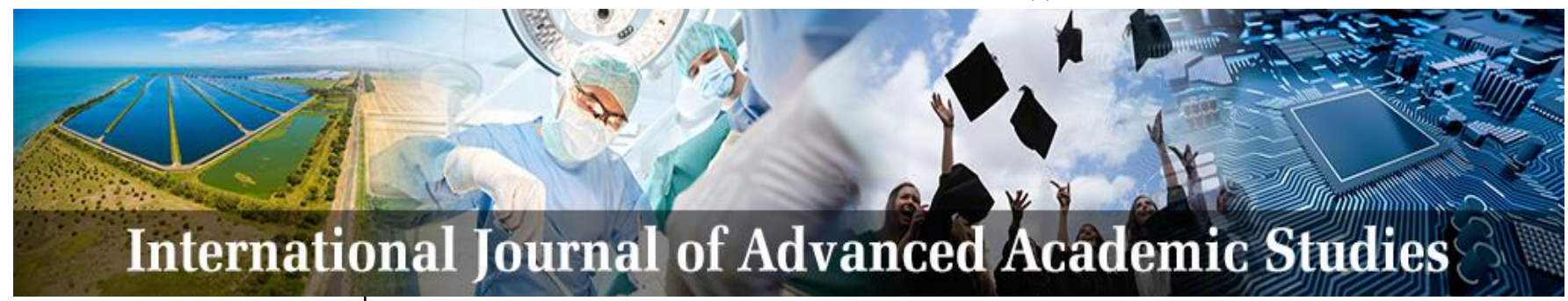

E-ISSN: 2706-8927

P-ISSN: 2706-8919

www.allstudyjournal.com IJAAS 2020; 2(3): 701-705

Received: 14-05-2020

Accepted: 18-06-2020

Namrata Kumari

M.A, Psychology, Lalit

Narayan Mithila University, Darbhanga, Bihar,

Department of Psychology, Darbhanga, Bihar, India

Corresponding Author: Namrata Kumari M.A, Psychology, Lalit Narayan Mithila University, Darbhanga, Bihar, Department of Psychology, Darbhanga, Bihar, India

\section{Interparental relationship conflict predict preschool children's adjustment on the basis of child parent percetions}

\section{Namrata Kumari}

DOI: $\underline{\text { https://doi.org/10.33545/27068919.2020.v2.i3j.272 }}$

\begin{abstract}
Interparental relationship conflict has been associated with a variety of child adjustment problems (for reviews, see Cummings \& Davies, 2010; Grych \& Fincham, 2001). For instance, exposure to interparental conflict has been shown to predict children's heightened emotional reactivity and maladaptive behavior in response to interadult conflict (Cummings \& Davies, 1994), as well as children's negative self-perceptions (Grych, Wachsmuth-Schlaefer, \& Klockow, 2002), poor behavioral adjustment (Jenkins, Simpson, Dunn, Rasbash, \& O'Connor, 2005), academic difficulties (Harold, Aitken, \& Shelton, 2007), problematic peer relations (Katz \& Woodin, 2002), and sleep disturbance (Keller \& El-Shiekh, 2011). Moreover, there has been much interest in understanding the mechanisms by which interparental discord may be linked to poor child adjustment, with appreciation for children as active processors of interparental conflict (Cummings \& Davies, 2010; McDonald \& Grych, 2006). Children's perceptions and cognitive-affective processing of their parents' relationship conflict are critical to their experience of such conflict, and subsequently, their adjustment both within and beyond their families. Clearly, parent perceptions contribute in important ways to understanding the relation between interparental conflict and children's adjustment; however, consideration of the child's perspective in relation to the parents' perspectives is necessary to understand the link.
\end{abstract}

Keywords: Interparental relationship, child adjustment, child parent

\section{Introductions}

\section{Aims of the Current Study}

Taken together, research to date has clearly demonstrated that interparental conflict has negative implications for children's adjustment. Further, prediction of school-aged children's adjustment from their own perceptions of interparental conflict has been shown to equal or surpass the prediction obtained by parents' reports. Finally, despite compelling evidence that preschoolers can provide reliable and valid information about individual and family functioning, research on children's perceptions of interparental conflict in this age group remains limited. Specifically, although recent studies by Ablow et al. (2009) ${ }^{[1]}$ and Miller et al. (2012) ${ }^{[18]}$ offer promising evidence for the links between young children's perceptions of interparental conflict and their behavioral adjustment, at least three significant questions remain. First, is it possible to demonstrate similar patterns of results in even younger, preschool-aged children? Second, can a pictorial, self-report measure of interparental conflict demonstrate adequate sensitivity to young children's perceptions? Third, can previous study findings be replicated by other researchers in other settings?

The present study was designed to address these questions by examining the links between child and parent perceptions of interparental conflict and child adjustment in a community sample of families with 4-year-old children. We had two specific hypotheses. First, based on previous research, we expected modest associations between parent and child reports of interparental conflict. Second, we expected higher levels of perceived interparental conflict to be associated with poorer behavioral adjustment, specifically lower child self-esteem (as reported by children, parents, and teachers) and more behavior difficulties (as reported by parents and teachers). Based on previous research with school-aged children, we anticipated that children's perceptions of interparental conflict would make a unique contribution to the prediction of their behavioral adjustment, beyond the prediction obtained by parents' reports of interparental conflict alone. That is, we expected that the prediction of children's selfesteem and behavior difficulties would be significantly improved by including children's reports of interparental conflict. 
Finally, to examine the possibility that the prediction obtained by children's reports depended on the level of interparental conflict, we also computed and examined an interaction term for parent and child reports.

\section{Method \\ Participants}

Participants were 78 four-year-old children (50 girls) and their parents. Families were recruited from a semi-rural area of the Northeast via advertising in the local newspaper and through letters sent to families identified through cross referencing birth, residency, and divorce records.

The county from which participants were drawn was $94 \%$ Anglo with a mean annual married couple household income of $\$ 55,806$, adjusted for inflation (U.S. Census Bureau, 1990). The current sample self-identified as $92 \%$ Anglo, with 1\% each Asian American, Native American, and Latino (the remaining 5\% chose not to indicate their ethnic or racial background). The average family income in the current sample was $\$ 55,579$ dollars $(S D=\$ 25,814$, range $\$ 12,000$ to $\$ 175,000)$. The educational level of the sample was high, with $86 \%$ of mothers $(M=15.79$ years of education, $S D=2.41$, range 12 to 22 years) and $85 \%$ of fathers $(M=15.93$ years of education, $S D=2.68$, range 11 to 23 years) reporting at least some college attendance.

The average length of marriage was 9.6 years $(S D=3.82)$. This was the first marriage for $90 \%$ of wives and $86 \%$ of husbands. Most families had at least two children (79\%), and the target child was the firstborn child for $47 \%$ of the sample.

\section{Procedures}

Families made two visits to the research lab. The first involved both parents and the child. In this visit, information about marital, parent-child, and individual functioning was collected. The second visit was a peer visit involving only the children. Only the family lab session was of interest to the current study, and only relevant measures and procedures from that session are described below.

Upon arriving at the lab, families were first given an overview of the upcoming research session. After providing informed consent, parents independently completed selfreport measures assessing various domains of parenting and marital relations, including interparental conflict. They also provided information about their children's functioning. In a different room with the help of a trained research assistant, children completed an interactive, videotaped measure of self-esteem and a pictorial questionnaire assessing their perceptions of their parents' interparental conflict. Following the completion of several interaction tasks and additional questionnaires, families were debriefed and paid $\$ 35$, and children were allowed to select a toy to take home.

\section{Measures \\ Demographics}

Parents independently provided demographic information, including their own educational attainment, family income levels, and a rating of the degree to which their resources were sufficient to meet family needs. Items were standardized, and the mean taken. The resulting index of socioeconomic functioning was internally consistent, $\alpha=$ .76 .

\section{Interparental conflict: Parent perceptions}

Parents' perceptions of interparental relationship conflict were obtained using the Conflict Tactics Scale (CTS; Straus, 1979), the most widely used index of relationship aggressive conflict. Individuals were asked to report upon their own behaviors and their partner's behaviors over the past year using a 6-point scale ranging from 0 (never) to 5 (more than once a month). The CTS was designed to assess behaviors in three different areas: Verbal Reasoning (e.g., "Tried to discuss the issue relatively calmly), Verbal Aggression (e.g., "Yelled and/or insulted"), and Physical Aggression (e.g., "Pushed, grabbed, or shoved the other"), but only the Verbal Aggression and Physical Aggression scales were of interest in the current study. In summarizing research on the CTS, Straus (1990) reported acceptable reliabilities, with internal consistencies ranging from .62 to .88 for Verbal Aggression $(M=.78)$ and .69 to .88 for Physical Aggression $(M=.82)$. In the current study, internal consistencies averaged .76 (range .62 for Wives' self-reports of Verbal Aggression to .94 for Wives' self-reports of Physical Aggression).

In order to reduce the number of variables, maternal and paternal reports of interparental relationship conflict were examined to determine if they could be combined to create a single parental score. Levels of husbands' and wives' Verbal and Physical Aggression were significantly correlated across self- and partner-reports $\left(M_{r}=.39\right.$, all $p$ s < $.002)$. Additionally, husbands' and wives' self-reports of Verbal and Physical Aggression were significantly correlated, with $r$ s ranging from .32 to $.36, p \mathrm{~s} \leq .004$, except for wives' and husbands' self-reports of Physical Aggression, $r(78)=.04, p=.71$. The lack of association for Physical Aggression reflects the substantial restriction in range of these behaviors for both partners in the current community sample.

Factor analytic studies of the CTS have suggested the possibility that the Verbal and Physical Aggression items may not represent cleanly separable factors. For instance, TenVergert, Kingma, and Gillespie (1990) ${ }^{[20]}$ suggested that the more violent items on the CTS represent a difficulty factor, and Caulfield and Riggs (1992) ${ }^{[2]}$ found verbal threats to load on the Physical Aggression factor rather than the Verbal Aggression factor. In the current community sample, the creation of a single score combining husbands' and wives' self- and partner-reports of Verbal and Physical Aggression resulted in a single, reliable index of interparental aggression $(\alpha=.88)$, which was significantly correlated with self-reports of husbands' and wives' Verbal and Physical Aggression $\left(M_{\mathrm{r}}=.60\right.$, range .32 to .79 , all $p$ s < $.005)$.

\section{Interparental conflict: Child perceptions}

Children's perceptions of interparental conflict were assessed using the Perceptions of Adult Conflict Tactics (PACTS; Dominguez, Markman, \& Rossman, 1993) ${ }^{[7]}$. This pictorial measure was adapted from the CTS and contains 6 items measuring interparental Verbal Aggression (e.g., "Some mothers yell and shout when the parents fight") and 10 items measuring interparental Physical Aggression (e.g., "Other fathers push, grab, or shove the mother when the parents fight"). The original measure utilized hand drawn pictures. In the current study, the original drawings were replaced with computer graphics in order to more precisely control for the specific variables of interest by insuring that the two pictures were identical in all other ways.

The PACTS questionnaire utilized a hierarchical, forcedchoice format taken from the widely used Pictorial Scale of Perceived Competence and Acceptance for Young Children (Harter \& Pike, 1984) ${ }^{[13]}$. Children were first presented with 
two pictures of parents arguing and asked to identify which of the two pictures was most like their parents. Within each pair, one drawing depicted the targeted interparental aggressive conflict, and the other did not. After choosing the picture most like their parents' behaviors, children were asked to indicate the degree to which their parents engaged in the specific behavior depicted, again choosing from two options. The advantage of the hierarchical, forced-choice format is that the child makes two relatively simple dichotomous decisions, thus allowing for a more fine grained determination of the child's perceptions than would otherwise be possible in this preschool sample. The responses then corresponded to a 4-point Likert type scale indicating the frequency $(1=$ never, $2=$ sometimes, $3=$ most of the time, 4 = always) of each aggressive act.

Dominguez (1995) ${ }^{[7]}$ reported internal consistencies ranging from .53 to .70 for the Verbal Aggression scale and from .77 to .87 for the Physical Aggression scale in a sample of 103 five-to 13-year-old children and their mothers. Test-retest reliabilities across a 4- to 6-week span averaged .66. Further, Dominguez reported significant positive correlations between the PACTS and mothers' reports of interparental Verbal and Physical Aggression from the CTS and significant negative correlations with parental relationship satisfaction.

Jones (2010) ${ }^{[15]}$ factor analyzed the PACTS and found that a single factor best described the measure. In the current study, an overall index of children's perceptions of interparental conflict was obtained by taking the mean across all Verbal Aggression and Physical Aggression items $(\alpha=.91)$

\section{Children's self-esteem}

Children's, parents', and teachers' reports of children's selfesteem were obtained. Children's reports were obtained using the 32-item Self-Concept Puppet Show (SPS; Eder, 1990) ${ }^{[8]}$. In the SPS, children respond to two puppets with sex-typed clothes and hair matched to the sex of the child. For each item, one puppet made a positive self-statement (e.g., "People like me") whereas the other puppet made an opposing statement (e.g., "People don't like me"). Children were then asked to indicate which puppet was most like them, with positive statements scored 1, and negative statements scored 0 .

Eder (1990) ${ }^{[8]}$ used live performances to interview children. In the current study, videotaped presentations of the puppets were used to ensure that the stimuli were consistent across participants. The original measure included 7 subscales: Social Closeness (e.g., "I have a best friend"), Aggression (e.g., "Sometimes it's fun to scare people"), Alienation (e.g., "Nobody wants to be around me"), Harm Avoidance (e.g., "It's not fun to ride in a fast car"), Stress Reaction (e.g., "I am grumpy a lot of the time"), Traditionalism (e.g., "I never do naughty things"), and Well-Being (e.g., "I'm usually happy"). In the current study, the individual subscales had internal consistencies of .35 to .58 , which were slightly lower than the original study values of .43 to .60. Thus, a multidimensional assessment of the child's self-concept did not appear to be indicated in the current sample. A total score was created by summing all items, and this score evidenced adequate reliability, $\alpha=.69$.

Parents' and teachers' perceptions of children's self-esteem were obtained using the Behavioral Rating Scale of Presented Self-Esteem in Young Children (Haltiwanger,
1995) [11]. This 15-item questionnaire assesses children's behaviorally expressed confidence (e.g., "Initiates activities confidently"), involvement (e.g., "Does not hang back; does more than watch, is involved"), goals (e.g., "Prefers activities that stretch his/her abilities; sets high goals"), selfdescriptions (e.g., "Describes self in generally positive terms"), and pride (e.g., "Shows pride in his/her work or accomplishments"). Parents' and children's preschool or daycare teachers responded using a 4-point rating scale. Total scores were created by taking the mean of all items. Ratings of child self-esteem were found to be internally consistent for teachers $(\alpha=.90)$, mothers $(\alpha=.83)$, and fathers $(\alpha=.85)$. Because mothers' and fathers' reports of children's self-esteem were highly correlated, $r(78)=$ $.64, p<.001$, and the combination of maternal and paternal reports resulted in an internally consistent scale, $\alpha=.90$, a combined parent report of children's self-esteem was used.

\section{Children's behavior difficulties}

Parents' and teachers' reports of children's behavior difficulties were obtained using the Conners scales. Parents completed the Conners Parent Questionnaire (Conners, 1985) [3], from which the 10-item Conners Abbreviated Parent Questionnaire (CAPQ) was extracted. Formed by taking the 10 most highly loaded symptoms from each of the scales on the original measure, the CAPQ score has been recommended for screening purposes (Sattler, 1992) [19] because it assesses common internalizing and externalizing problems. Parents rated children's behavior difficulties including "Cries easily or often," "Destructive," and "Easily frustrated in efforts" using a 0 (not at all) to 3 (very much) scale. Total scores are then converted to $T$-scores, with higher values indicating more behavior difficulties. In the current sample, the CAPQ evidenced good internal consistency, with $\alpha=.78$ for mothers' reports and $\alpha=.71$ for fathers' reports. Because parents' CAPQ scores were significantly correlated, $r(78)=.50, p<.001$, and the combination of parents' reports resulted in an internally consistent scale, $\alpha=.82$, a single index of children's behavioral adjustment was created by taking the mean of maternal and paternal CAPQ $T$-scores.

Children's preschool or daycare teachers completed the Conners Teacher Questionnaire (Conners, 1985) ${ }^{[3]}$, from which the 10-item Conners Abbreviated Teacher Questionnaire (CATQ) was extracted. The CATQ evidenced very good internal consistency, $\alpha=.89$.

\section{Go to}

Results

The results are presented in two sections. First, descriptive information about major study variables, including bivariate correlations between parent and child conflict perceptions, is presented. These correlations were used to examine the hypothesis that parents and children would offer unique perspectives on interparental conflict, with only modest associations predicted between child- and parent-report. Correlations were also used to examine, in a bivariate fashion, the associations between child and parent perceptions of interparental conflict and children's selfesteem and behavioral adjustment. Second, hierarchical multiple regressions are presented in which children's selfesteem and behavior difficulties are predicted from parentreported interparental relationship conflict, child-reported interparental conflict, and the interaction of parent- and 
child-reports. These analyses were conducted to examine the hypothesis that children's perceptions would add to the prediction of child functioning obtained by parents' reports of interparental conflict.

\section{Descriptive Statistics}

Means, standard deviations, and bivariate correlations for study variables are presented in Table 1. Child gender was dummy coded ( 0 for boys, 1 for girls) and examined in relation to all outcome variables and all reports of interparental conflict. As shown in Table 1, no correlations between gender and other study variables reached significance. Thus, child gender was dropped from subsequent analyses. Similarly, socioeconomic status was correlated with only one of five outcome variables. Regressions were then computed with and without socioeconomic status included as a predictor. As the pattern of results was identical and socioeconomic status was not a significant predictor in any regression, only the regressions omitting socioeconomic status are presented below.

Chiled esteem As shown in Table 2, child-reported selfesteem was significantly predicted by interparental conflict, $R^{2}=.26, F(3,74)=8.74, p<.001$, but this relation was driven by child-reported interparental conflict. Neither parent-reported interparental conflict nor the parent-bychild-report interaction term was significantly associated with child-reported self-esteem. In contrast, higher childreported interparental conflict was significantly associated with lower self-esteem.

\section{Parent-reported child self-esteem}

Parent-reported child self-esteem was not predicted by interparental conflict, $R^{2}=.04, F(3,74)=1.09, p=.36$. Neither parent-reports, child-reports, nor the parent-bychild-report interaction term was associated with parentreported child self-esteem.

\section{Teacher-reported child self-esteem}

Teacher-reported child self-esteem was associated with interparental conflict, $R^{2}=.07, F(3,64)=2.76, p=.049$. Teacher-reported child self-esteem was significantly negatively predicted by parent-reported interparental conflict and marginally negatively predicted by the parentby-child-report interaction term, but not predicted by childreported interparental conflict.

\section{Prediction of Children's Behavioral Difficulties from Interparental Conflict}

Parent- and teacher-reported child behavioral difficulties were examined in separate hierarchical regressions. As shown in Table 2, parent-reported interparental conflict was again entered on the first step, followed by child-reported interparental conflict on the second step, and then the parent-by-child-report interaction term on the third step.

\section{Parent-reported child behavior difficulties}

Parent-reported child behavior difficulties were significantly predicted by interparental conflict, $R^{2}=.12, F(3,74)=$ $4.53, p=.006$. Higher parent- and child-reports of interparental conflict were both significantly associated with more behavioral difficulties, but the parent-by-child-report interaction term did not add to prediction.

\section{Teacher-reported child behavior difficulties}

Teacher-reported child behavior difficulties were significantly predicted by interparental conflict, $R^{2}=.19$,
$F(3,63)=4.92, p=.004$. Both higher child-reported interparental conflict and the parent-by-child-report interaction term were predictive of more child behavior difficulties.

To decompose the significant interaction term, the sample was split on parent-reported interparental conflict. As shown in Figure 1, when parents reported higher levels of interparental conflict, child-reported conflict was significantly positively associated with teacher-reported behavior difficulties, $R^{2}=.25, B=4.95, S E_{B}=1.60, \beta=.50$, $p=.004$; however, this relation was not significant when parents reported low interparental conflict, $R^{2}=.04, B=$ $1.70, S E_{B}=1.43, \beta=.20, p=.24$.

\section{References}

1. Ablow JC, Measelle JR. Berkeley Puppet Interview: Administration and scoring system manuals. Berkeley, CA: University of California Press, 1993. [Google Scholar]

2. Caulfield MB, Riggs DS. The assessment of dating aggression: Empirical evaluation of the Conflict Tactics Scale. Journal of Interpersonal Violence. 1992; 7:549558. [Google Scholar]

3. Conners CK. The Conners Rating Scales: Instruments for the assessment of childhood psychopathology. Washington, D. C: Unpublished manuscript, Children's Hospital National Medical Center, 1985. [Google Scholar]

4. Dispute and resolution. New York, NY: Guilford; [Google Scholar Cummings EM, Davies P. Children and marital conflict, 1994. The impact of family]

5. Cummings EM, Davies PT. Interparental aggression and children: An emotional security perspective. New York, NY: Guilford, 2010. [Google Scholar 6]

6. Dominguez ML. Children's Reactions to Adult Conflict Tactics. Denver, CO: Unpublished Dissertation University of Denver, 1995. [Google Scholar]

7. Dominguez ML, Markman HJ, Rossman BBR. The Perceptions of Adult Conflict Tactics Scale (PACTS) Unpublished measure, University of Denver, CO, 1993. Google Scholarversity of Denver, 1995. [Google Scholar]

8. Eder RA. Uncovering young children's psychological selves: Individual and developmental differences. Child Development. 1990; 61:849-863. [PubMed] [Goo]

9. Grych JH, Fincham FD. editors. Interparental conflict and child development: Theory, research, and application. Cambridge, UK: Cambridge University Press, 2001. [Google Scholargle Scholar]

10. Grych JH, Wachsmuth-Schlaefer T, Klockow LL. Interparental aggression and young children's representations of family relationships. Journal of Family Psychology. 2002; 16:259-272. [PubMed] [Google Scholar]

11. Haltiwanger JT. Relations between dimensions of parenting and presented self-esteem in young children. Dissertation Abstracts International: Section B: The Sciences and Engineering. 1995; 56(4-B):2351. [Google Scholar]

12. Harold GT, Aitken JJ, Shelton KH. Inter-parental conflict and children's academic attainment: A longitudinal analysis. Journal of Child Psychology and Psychiatry. 2007; 48:1223-1232. [PubMed] [Google Scholar] 
13. Harter S, Pike R. The Pictorial Scale of Perceived Competence and Social Acceptance for Young Children. Child Development. 1984; 55:1969-1982. [PubMed] [Google Scholar]

14. Jenkins J, Simpson A, Dunn J, Rasbash J, O’Connor TG. Mutual influence of interparental aggression and children's behavior problems: Shared and nonshared family risks. Child Development. 2005; 76:24-39. [PubMed] [Google Scholar]

15. Jones KG. Through the eyes of a child: Do children's perceptions mediate the relationship between marital conflict and peer conflict tactics? Pasadena, CA: Unpublished master's project, Fuller Theological Seminary, 2010. [Google Scholar]

16. Katz LF, Woodin EM. Hostility, hostile detachment, and conflict engagement in marriages: Effects on child and family functioning. Child Development. 2002; 73:636-651. [PubMed] [Google Scholar]

17. Keller P, El-Sheikh M. Children's emotional security and sleep: Longitudinal relations and directions of effects. Journal of Child Psychology and Psychiatry. 2011; 52:64-71. [PubMed] [Google Scholar]

18. Miller LE, Howell KH, Graham-Bermann SA. Predictors of preschoolers' appraisals of conflict in families experiencing intimate partner violence. Journal of Interpersonal Violence. 2012; 27:568-586. [PubMed] [Google

19. Sattler JM. Assessment of children. 3rd ed. San Diego, CA: Author; Rev. and updated, 1992. [Google Scholar Scholar]

20. TenVergert E, Kingma J, Gillespie MW. Dichotomous items and extreme item difficulties: Factor analysis of the ConfGoogle ScholarGoogle Scholar, 1990. 